\title{
Simultaneous en-bloc pancreas and kidney transplantation from a small paediatric donor after circulatory death
}

DOI:

10.1111/ajt. 15044

\section{Document Version}

Accepted author manuscript

Link to publication record in Manchester Research Explorer

\section{Citation for published version (APA):}

Dobbs, S., Shapey, I. M., Summers, A., Moinuddin, Z., van Dellen, D., \& Augustine, T. (2018). Simultaneous enbloc pancreas and kidney transplantation from a small paediatric donor after circulatory death. American Journal of Transplantation. https://doi.org/10.1111/ajt.15044

\section{Published in:}

American Journal of Transplantation

\section{Citing this paper}

Please note that where the full-text provided on Manchester Research Explorer is the Author Accepted Manuscript or Proof version this may differ from the final Published version. If citing, it is advised that you check and use the publisher's definitive version.

\section{General rights}

Copyright and moral rights for the publications made accessible in the Research Explorer are retained by the authors and/or other copyright owners and it is a condition of accessing publications that users recognise and abide by the legal requirements associated with these rights.

\section{Takedown policy}

If you believe that this document breaches copyright please refer to the University of Manchester's Takedown Procedures [http://man.ac.uk/04Y6Bo] or contact uml.scholarlycommunications@manchester.ac.uk providing relevant details, so we can investigate your claim.

\section{OPEN ACCESS}



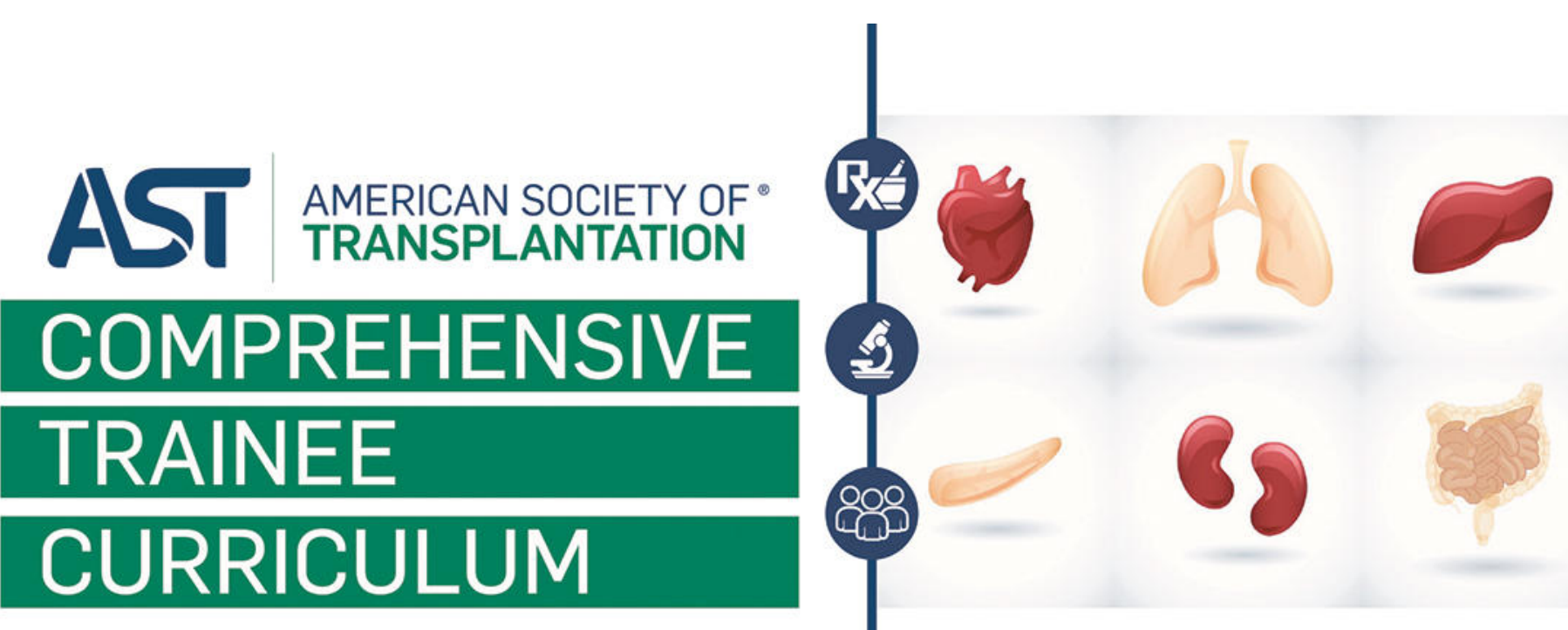

\section{COMPREHENSIVE TRAINEE CURRICULUM}

\section{WATCH 52 ONLINE LESSONS INCLUDING:}

- Adult and Pediatric Liver

- Adult Cardiac and Pulmonary

- Abdominal Transplant Surgery
- Cardiothoracic Transplant Surgery

- Adult and Pediatric Kidney

- Transplant Pharmacy
Solid organ transplantation is a multidisciplinary field, leading to a diverse community of professionals within the AST. As a result, it is often necessary for trainees to have extensive knowledge of all areas of transplantation-not just their specialty.
Check out this brand new resource, meant to supplement the training trainees and fellows receive at their university or hospital.

\$50 members / \$200 non-members 
Article type : Case Report

Simultaneous en-bloc pancreas and kidney transplantation from a small paediatric donor after circulatory death

\section{Authors}

S Dobbs ${ }^{1}$, IM Shapey ${ }^{1}$, A Summers ${ }^{1}$, Z Moinuddin $^{1,2}$, D van Dellen $^{1}$, T Augustine $^{1,2}$

\section{Affiliations}

${ }^{1}$ Department of Renal and Pancreatic Transplantation, Manchester University NHS Foundation Trust, Oxford Road, Manchester, UK

${ }^{2}$ Faculty of Biology, Medicine and Health, University of Manchester, Oxford Road, Manchester, UK

\section{Corresponding author email}

Sian Dobbs

sian.dobbs@nhs.net

\section{Abbreviations}

SPKT simultaneous pancreas and kidney transplant

DCD declaration of circulatory death

This article has been accepted for publication and undergone full peer review but has not been through the copyediting, typesetting, pagination and proofreading process, which may lead to differences between this version and the Version of Record. Please cite this article as doi: 10.1111/ajt.15044

This article is protected by copyright. All rights reserved. 


\section{Abstract}

Simultaneous pancreas and kidney transplantation (SPKT) is an effective treatment option for patients with type 1 diabetes and end stage renal disease. Increasing demands for organs for transplantation coupled with a rise in age and size of adult donors has led to greater utilization of paediatric donors, and with good outcomes. Nonetheless, there remains reticence amongst transplant surgeons to transplant pancreases from small paediatric donors despite the optimal characteristics and macroscopic features of the younger pancreas. We report a successful case of SPKT from a small paediatric donor and explore the aspects of potential concern that might have led some clinicians to decline these organs. We also discuss the measures taken to overcome potential obstacles to successful transplantation from this donor source, and the rationale behind them.

\section{Introduction}

Simultaneous pancreas and kidney transplantation (SPKT) is an effective treatment option for patients with type 1 diabetes and end stage renal disease. ${ }^{1}$ Donor organ quality is directly related to transplantation outcomes; in pancreas transplantation, donor age and obesity are major determinants of successful transplantation. ${ }^{2,3}$ Increasing demands for organs for transplantation coupled with a rise in age and size of adult donors has led to greater utilization of paediatric donors, and with good outcomes. $^{4-12}$ Nonetheless, there remains reticence amongst transplant surgeons to transplant pancreases from small paediatric donors despite the optimal characteristics and macroscopic features of the younger pancreas. In some circles, small paediatric pancreas donors continue to be considered marginal due to concerns over insufficient pancreatic beta-cell mass to meet adult metabolic requirements ${ }^{13}$, size matching ${ }^{4}$ and the increased risk of thrombosis. ${ }^{14}$ Paediatric donation for liver, kidney and intestinal transplantation is common, not least because of the important consideration of matching the size of the donor to the recipient. The pancreas, however, is almost exclusively transplanted into adult recipients, and hence size matching is afforded an entirely different consideration.

This article is protected by copyright. All rights reserved. 
We report a successful case of SPKT from a small paediatric donor and explore the aspects of potential concern that might have led some clinicians to decline these organs. We also discuss the measures taken to overcome potential obstacles to successful transplantation from this donor source, and the rationale behind them.

\section{Case report}

A 43-year-old female with complex type 1 diabetes (dialysis dependence, retinopathy and hypoglycaemia unawareness) was admitted for SPKT. She had a disease duration of 35 years and required 50-60 units of insulin a day. The donor was a 4-year-old female who was involved, as a pedestrian, in a road traffic collision at 40-50 miles per hour. The donor suffered a cardiac arrest and extensive cranial and thoraco-abdominal injuries which necessitated emergency laparotomy revealing distended small and large bowel loops, but no major visceral injuries. The donor was transferred to a regional trauma unit with a laparostomy (open abdomen) and vacuum dressing in situ. The patient suffered two further cardiac arrests prior to cessation of ventilation. Brain stem death could not be declared and, therefore, upon withdrawal of life sustaining treatment and declaration of circulatory death, a supra-rapid laparotomy and en-bloc organ procurement was performed with cold in-situ preservation using University of Wisconsin solution. The time from withdrawal of treatment to asystole was 7 minutes, and was followed by a further 10 minutes until cold preservation was commenced.

The weight and height of the donor and recipient were $16 \mathrm{Kg} / 111 \mathrm{~cm}$ and $64 \mathrm{Kg} / 166 \mathrm{~cm}$ respectively. HLA mis-match was 1:2:2. The organs had very good pre-donation function and were of macroscopically excellent quality (non-fatty, non-fibrotic). A joint decision was made by two experienced surgeons to accept and transplant the offered organs, one of whom also performed the organ procurement procedure. Via a modified Rutherford-Morrison incision the pancreas and single left kidney ( 1 artery, 1 vein, 1 ureter) were transplanted en-bloc into the extra-peritoneal right iliac fossa (Figures 1). An aortic patch containing the left renal artery, SMA and coeliac artery was anastomosed to the recipient's right common iliac artery. The left renal vein and portal vein were anastomosed consecutively to the recipient's common iliac vein, whilst the ureter was anastomosed to the bladder in the standard fashion. No anti-vasospasm therapy was applied. Reperfusion of the

This article is protected by copyright. All rights reserved. 
organs was brisk and uniform. Finally, the peritoneum was breached to facilitate anastomosis of the duodenum to a loop of terminal ileum and thereafter both the transplanted pancreas and kidney were intra-peritonealised. The total ischaemic time was 17 hours and 42 minutes (re-warm ischaemia 73 minutes). Standard therapeutic anti-coagulation (weight adjusted intravenous heparin) and immunosuppression (Campath, Tacrolimus, Mycophenolate) regimens were followed postoperatively. However, a return to theatre to control active bleeding from the duodenal anastomosis mandated a change from therapeutic to prophylactic anti-coagulation regimens - this was complicated further by an upper limb deep vein thrombosis. At 8 months post-transplantation the patient had excellent dual graft function with normal blood glucose levels and a stable creatinine value of $\sim 120 \mathrm{pmol} / \mathrm{L}$.

\section{Discussion}

Transplantation of kidneys from paediatric donors into adult recipients is a well-established technique with successful outcomes, even from very small donors. ${ }^{15-18}$ In recent years, the technical feasibility of pancreas transplantation from paediatric donors has also been demonstrated. ${ }^{4-14}$ Yet, reports from small donors are few in number, and may reflect ongoing concerns within the pancreas transplant community regarding the use of such donors. Low blood flow and venous pressures in the recipients' central venous system predispose donor pancreases, especially organs with small calibre portal veins, to venous stasis and hence the risk of thrombosis. Meanwhile, the multiple anastomoses required to reconstruct the donor pancreas arterial vasculature increases the risk of stenosis, especially in smaller vessels. To overcome this, transplantation of the pancreas and kidney from small donors has largely been performed en bloc.,11 In some instances, dual kidneys have been transplanted along with the pancreas, meaning that only a single aortic conduit and caval outflow was required. ${ }^{11}$ Other techniques, such as the piggy-back, anastomosed the reconstructed pancreas onto the aorto-caval conduits which were, themselves, anastomosed to the recipient. ${ }^{12}$

However, the published en bloc techniques have their limitations. ${ }^{4,6,12}$ First, the transplantation of dual kidneys from a young donor with excellent function, precludes another recipient from receiving a potentially excellent kidney graft. Paediatric donors are in short supply, especially for paediatric recipients, and hence there is an argument against promoting dual kidney transplants from these

This article is protected by copyright. All rights reserved. 
donors. Our technique enabled the maximum number of recipients to benefit from the donor. Second, the portal vein requires its own anastomosis irrespective of whether this is to a donor conduit or to the recipient's native vein. Separate anastomoses for the portal vein and renal vein means that, in the event of a losing the pancreas graft secondary to a portal vein thrombus, the viability of the kidney graft would not be compromised. This is because a thrombus from a separate and more proximal portal vein anastomoses would propagate cranially, and a transplant pancreatectomy could be performed without disrupting the venous anastomosis from the kidney. Finally, the single arterial anastomosis of the aortic conduit (containing the coeliac axis, superior mesenteric artery and left renal artery) minimised the potential risks from disrupted perfusion, bleeding, stenosis, and pseudoaneurysm.

In this reported case, organ donation followed the declaration of circulatory death (DCD); this is standard practice in the UK for such a young donor. ${ }^{18}$ Other reported cases of small paediatric pancreas donation have followed the diagnosis of brain death. ${ }^{5,7}$ This distinction is important because the additional hypoxic insult experienced during the warm ischaemic time associated with DCD donation drives a more time-critical retrieval and transplantation process. Measures to reduce both warm and cold ischaemic time, such as eliminating unnecessary and complex vascular anastomoses, are likely to play a significant role in improving outcomes.

Donor pancreas mass poorly correlates with post-transplantation graft function, and islet cell yield from very small donors may result in excellent metabolic function in adult recipients ${ }^{4,10}$. SPKT from paediatric donors are reported to have superior long-term outcomes compared with adult donors. ${ }^{5,10}$ At 5 years follow up, mean (SD) glucose levels and $\mathrm{HbA1c}$ levels were lower in recipients of paediatric donors $(85.3 \pm 13 \mathrm{mg} / \mathrm{dL}$, respectively) vs adult donors (Glucose: 85.3 [13] mg/dL vs 95.1 [29] mg/dL, $\mathrm{p}=0.001$. Hb A1c: 5.5 [1.0] \% vs 5.9 [3.5]\%, $\mathrm{p}=0.010) .{ }^{5}$ Moreover, Krieger et al found no significant difference in graft survival when "non-ideal" donors (including paediatric donors) were utilised compared with grafts from "ideal" adult donors and supported the further expansion of the pancreas donor pool to include these groups. ${ }^{8}$ Biglarnia et al demonstrated successful utilisation of very small paediatric donors (age 1.5-26 months, weight 4-15kg) and achieved excellent graft function, despite presumed graft immaturity and high recipient/donor weight ratio. ${ }^{14}$ Historical concerns that paediatric pancreases are suboptimal, because of a presumption that lower islet mass

This article is protected by copyright. All rights reserved. 
from paediatric donors are incapable of meeting the metabolic requirements of adult recipients are unfounded. ${ }^{5,10}$

It has been demonstrated that infant pancreases are a rich source of islet cells. ${ }^{19}$ It has also been suggested that due to reduced exposure of paediatric islet cells to environmental and genetic stressors, paediatric pancreases are more resilient to the hypoxic stress following transplantation, and have an increased replicative capacity compared to adult donors. ${ }^{5}$ The adaptive capability of very small paediatric pancreases has been demonstrated, with recipient computed tomographic scans identifying somatic growth of up to $140 \%$ over a median follow up of 750 days. ${ }^{14}$ Furthermore, paediatric $\beta$ cells have superior insulin secretory regulation compared to adult cells, possibly due to the reduction of intracellular ATP concentration associated with advancing age. ${ }^{20}$ Despite this, paediatric donors continue to be underutilised for pancreas transplantation because of an inaccurate assumption over insufficient levels of islet cell mass.

In conclusion, pancreas transplantation from small paediatric donors after circulatory death is both safe and efficacious. Our reported technique facilitates the maximum utilisation of all organs for transplantation whilst minimising the risks associated with excessively complex vascular reconstruction. Continued characterisation of this source of high quality organs as marginal is inappropriate.

\section{Disclosure}

The authors of this manuscript have no conflicts of interest to disclose as described by the American Journal of Transplantation.

\section{Figure Legends}

Figure 1: En-bloc pancreas and kidney graft prior to transplantation. A - Aortic patch; D - Duodenum; LK - Left kidney; LRV - Left renal vein; PV - Portal vein; U - ureter

This article is protected by copyright. All rights reserved. 


\section{References}

1. Jiang AT, BHSc, Rowe N, Sener A, Luke P. Simultaneous pancreas-kidney transplantation: The role in the treatment of type 1 diabetes and end-stage renal disease. Canadian Urological Association Journal. 2014;8(3-4):135-138.

2. Salvalaggio PR, Schnitzler MA, Abbott KC, Brennan DC, Irish W, Takemoto SK, Axelrod D, Santos LS, Kocak B, Willoughby L, Lentine KL. Patient and graft survival implications of simultaneous pancreas kidney transplantation from old donors. Am J Transplant. 2007 Jun;7(6):1561-71

3. Humar A, Ramcharan T, Kandaswamy R, Gruessner RW, Gruessner AG, Sutherland DE.The impact of donor obesity on outcomes after cadaver pancreas transplants. Am J Transplant. 2004 Apr;4(4):605-10.

4. H.G. Illanes, C.M. Quarin, R. Maurette, N.G. Sánchez, L. Reniero, and D.H. Casadei. Use of Small Donors $(<28 \mathrm{Kg})$ for Pancreas Transplantation Transplantation Proceedings, 41, $2199-2201(2009)$

5. Fernandez, L. A., Turgeon, N. A., Odorico, J. S., Leverson, G., Pirsch, J. D., Becker, B. N., Chin, L. T., Becker, Y. T., Knechtle, S. J., Foley, D. P., Shames, B. D., Kalayoglu, M., D'Alessandro, A. M. and Sollinger, H. W. (2004), Superior Long-Term Results of Simultaneous Pancreas-Kidney Transplantation from Pediatric Donors. American Journal of Transplantation, 4: 2093-2101.

6. Alexis Buggenhout, Anh Dung Hoang, Florence Hut, Jean B. Lekeufack, Maria-Antoniela Bali and Luc De PauwPediatric En Bloc Dual Kidney-Pancreas Transplantation Into an Adult Recipient: a Simplified Technique. Benefits of the en bloc kidney-pancreas transplantation technique in pediatric donors. American Journal of Transplantation 2004; 4: $663-665$

7. Sageshima, J., Ciancio, G., Chen, L., Selvaggi, G., Nishida, S., Akpinar, E., Nesher, E., Romano, A., Misawa, R. and Burke, III, G. W. (2010), Combined Pancreas and En Bloc Kidney Transplantation Using a Bladder Patch Technique From Very Small Pediatric Donors. American Journal of Transplantation, 10: 2168-2172.

8. Krieger NR, Odorico JS, Heisey DM, et al. Underutilisation of pancreas donors. Transplantation. 2003;75:1271-1276

This article is protected by copyright. All rights reserved. 
9. Schenker $\mathrm{P}$ Flecken $\mathrm{M}$, Vonend $\mathrm{O}$, et al. En bloc retroperitoneal pancreas-kidney transplantation with duodenoduodenostomy using pediatric organs. Transplant Proc. 2009 Jul-Aug;41(6):2643-5.

10. C.Socci, E.Orsenigo, I.Santagostino ${ }^{a}$ et al. Pancreases From Pediatric Donors Restore Insulin Independence in Adult Insulin-Dependent Diabetes Mellitus Recipients. Transplant Proc. 2010;42:2068-2070

11. Mario Spaggiari; Martha Bissing; Maya Campara et al. Pancreas Transplantation From Pediatric Donors: A United Network for Organ Sharing Registry Analysis. Transplantation. 101(10):2484-2491,

12. Matthias Waldner, Thomas Ba" chler, Erik Schadde, Marc Schiesser, Franz Immer, Pierre-Alain Clavien and Jens Gunther Brockmann New surgical technique for pediatric en-bloc kidney and pancreas transplantation: the pancreas piggy-back Transplant International 2013 (26) 30-33

13. Luis H. Toledo-Pereyra, Javier Castellanos, Guillermo Manifacio, Richard C. Lillehei. Basic Requirements of Pancreatic Mass for Transplantation. Arch Surg. 1979;114(9):1058-1062.

14. Biglarnia A, Bennet W, Nilsson T et al. Utilisation of small paediatric donors including infants for pancreas and kidney transplantation: exemplification of surgical technique and the surveillance. Letter to the Editor. Annals of Surgery: August 2014 - Volume 260 Issue 2 - p e5-e7

15. Foss A, Gunther A, Pal-Day L et al. Long term clinical outcome of paediatric kidneys transplanted to adults.Nephrol Dial Transplant (2008) 23: 726-729

16. Csapo Z, Knight RJ, Podder $\mathrm{H}$ et al. Long-term outcomes of single paediatric vs. ideal adult renal allograft transplants in adult recipients. Clin Transplant. 2006 JulAug;20(4):423-6.

17. Dharnidharka VR, Stevens G, Howard RJ. En-bloc kidney transplantation in the United states: an analysis of united network of organ sharing (UNOS) data from 1987 to 2003. Am J Transplant. 2005 Jun;5(6):1513-7.

18. Brierley J, Hasan A. Aspects of deceased organ donation in paediatrics. $\mathrm{Br} \mathrm{J}$ Anaesth. 2012 Jan;108 Suppl 1:i92-5.

This article is protected by copyright. All rights reserved. 
19. Sutherland DE, Matas AJ, Steffes MW, Najarian JS. Infant human pancreas. A potential source of islet tissue for transplantation. Diabetes. 1976;25:1123-1128.

20. Sung-Hee Ihm, Ippei Matsumoto, Toshiya Sawada, Masahiko Nakano, Hui J.Zhang, Jeffrey D. Ansite, David E.R. Sutherland, Bernhard J. Hering. Effect of Donor Age on Function of Isolated Human Islets. Diabetes May 2006, 55 (5) 1361-1368

\section{Figure 1}

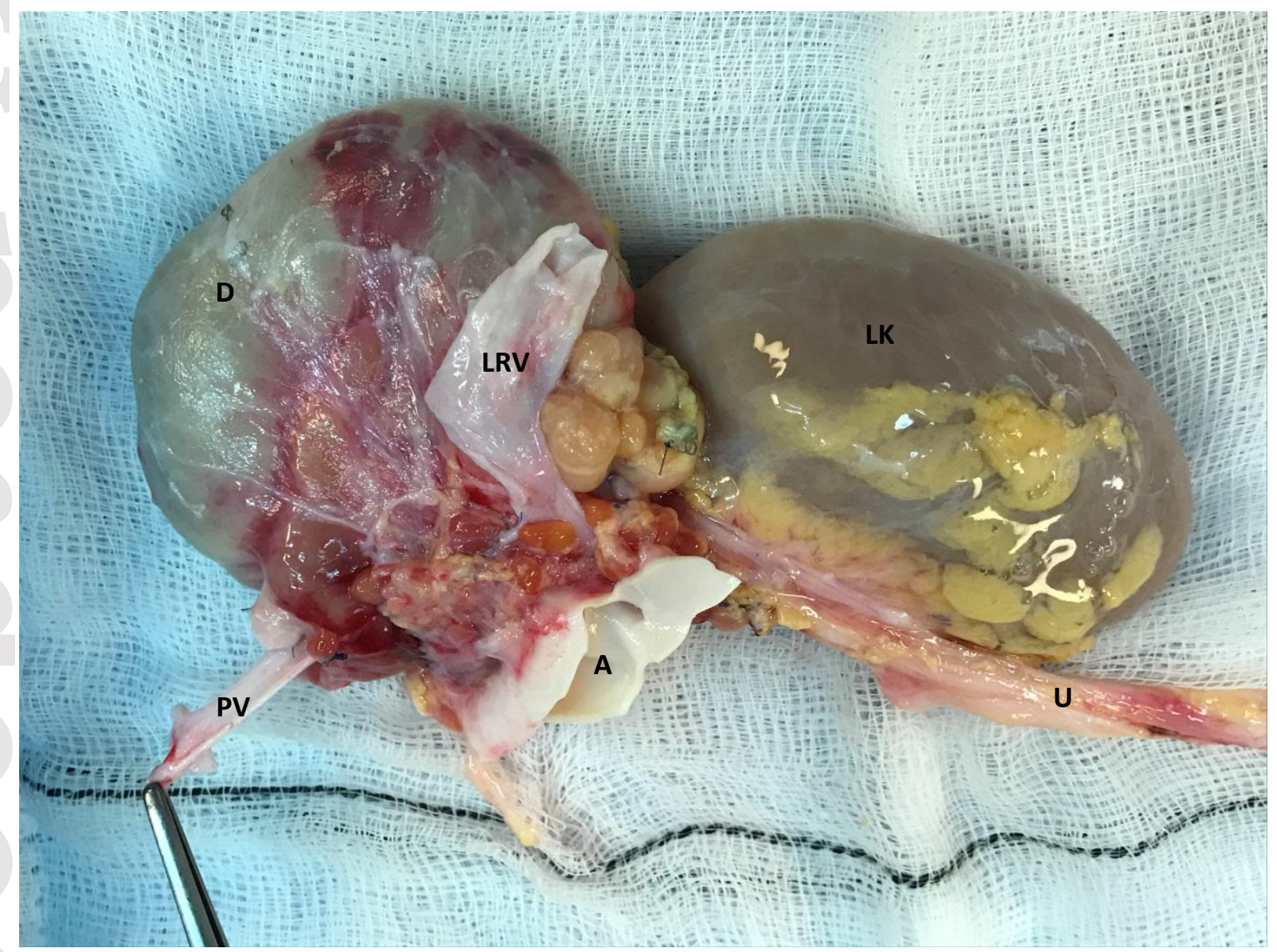

En-bloc pancreas and kidney graft prior to transplantation.

A - Aortic patch; D - Duodenum; LK - Left kidney; LRV - Left renal vein; PV - Portal vein; U - ureter

This article is protected by copyright. All rights reserved. 